\title{
15 SOME ASPECTS OF MATHEMATICAL MODELLING OF PHYSICAL, CHEMICAL AND BIOLOGICAL PROCESSES IN NATURAL LEACHATE TREATMENT SYSTEMS
}

\author{
Mikhail Romanov \\ St.Petersburg State Technical University, Russia
}

\begin{abstract}
The problem of natural ecosystems protection against pollution by waste water is very actual in many countries, including Russia. Yearly water consumption by industry and agriculture of Russia is about $75-80$ billion cubic meters. Only $3-4 \%$ of total volume of the industrial and municipal waste water is purified to establish norms. However basic quantity of waste water is discharged without treatment in natural reservoirs. The most dangerous pollutants of water are pesticides, nitrates, sulfates, phosphoric substances and salts of heavy metals [1].

The methods of waste water treatment can be divided on two groups: a) the methods of treatment in artificial plants (for example, aerated lagoons; biological filters and etc.); b) the methods of treatment in natural systems (for example, fields of irrigation; filtration fields; wetlands and etc.). The choice of the treatment depends on composition and concentration of waste substances in leachate and economical expediency.

During projecting and building of any water protection constructions, it is necessary to develop the theoretical basis. However, the exact calculations of hydrodynamic processes of convective - diffusive transfer in space and in time and physical-chemical transformation of non-conservative substances are impossible because of extreme complicity in most cases [2]. Moreover, using of exact analytical models is non-effective because of considerable inexactitude of initial information. The investigations of processes of the convective diffusive transfer and transformation of substance in natural conditions are very complex and expensive task. Therefore, the methods of mathematical modeling are the most favorable in this case.
\end{abstract}

\section{KEYWORDS}

Mathematical models; natural leachate treatment system.

Main processes of entering and transformation of pollutants and its quantity evaluation

After analyzing a plenty of activities on this problem it is necessary to make some remarks. For more correct evaluation of the natural ecosystems pollution and processes of selfcleaning, it is necessary: a) to count multiplicity of routes of pollutants entry in water; b) to use the complex approach to a problem of sewages clearing taking into account a role of different media (soil, plants, water). 
The scheme of main processes of entering and transformation of pollutants in different media is shown on Fig. 1. For modeling of physical, chemical and biological processes of waste water treatment at the natural ecosystems we recommend to use this scheme.

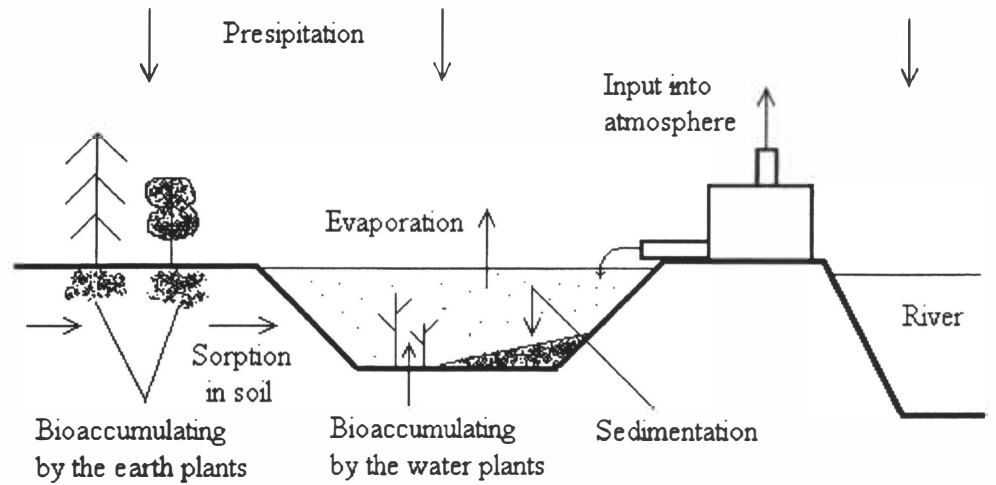

Figure 1. The scheme of main processes of entering and transformation of pollutants in different media.

Apparently, that we should allow for processes lead to increasing of pollutants concentration in natural waters (the first group) and inverse processes (the second group).

The following main processes concern to the first group:

- the direct entry of sewages in water or earth ecosystems;

- the precipitation of pollutants from atmosphere;

- the outwash of pollutants from a surface of the earth;

- the desorption of pollutants from soil;

- the outwashing from bottom deposits.

The following main processes concern to the second group:

- the sorption of pollutants in soils;

- the bioaccumulating of pollutants by the earth plants;

- the dilution of sewages;

- the evaporation;

- the sedimentation of pollutants;

- the bioaccumulating and degradation of pollutant substances by water plants and microorganisms;

- the biochemical and physical-chemical processes of transformation of pollutants in water.

We will analyze the processes which lead to decreasing of pollution substances concentration in natural waters in detail.

\section{1) The sorption of pollutants in soils.}

The most important factor of pollutants migration into soils is convective transfer. The real speed of movement of the water particle (the average speed of particle in pores) uses as main characteristics of convective transfer speed.

It depends on the filtration speed: 


$$
U=V / n_{e}
$$

here $n_{e}=n^{*}(1+\beta) / \beta$ - the effective porosity; $n$ - the free porosity of a rock; $\beta$ - the coefficient of matter distribution between fluid and firm phases of a soil.

Value of $\beta$ - coefficient changes from thousand lobes (for well sorbed materials) to 30 (for badly sorbed material, for example, for anions $\mathrm{NO}_{3}{ }^{-}, \mathrm{Cl}^{-}, \mathrm{SO}_{4}{ }^{2-}$ and etc.).

The reaching time of a reservoir by the contaminated underground waters is determined under the formula:

$$
t=X \times n_{e} / V=X \times n_{e} / K \times i
$$

here $\mathrm{X}$ - the spacing interval from border of area of underground waters contamination underground waters up to the river or reservoir in which underground waters are discharged; $\mathrm{K}$ - the coefficient of water-bearing rocks filtration; $\mathrm{i}$ - the slope of a flow of underground waters identified by the map of hydroisohypses of aquifer [3].

The consumption of the contaminated underground waters $\left(Q_{p}\right)$ in a reservoir and quantity of discharged pollutants (W) in a reservoir for computational period is determined under the formula approximately [3]:

$$
\begin{aligned}
& Q_{p}=m \times L \times K \times i \\
& W=Q_{p} \times C_{\mathcal{d}}=C_{a v} \times m \times L \times K \times i
\end{aligned}
$$

here $\mathrm{m}$ - the average power of aquifer in a near-shore area; $\mathrm{L}$ - the width of inshore segment where discharge of the contaminated underground waters takes place; $\mathrm{C}_{\mathrm{av}}$ - the mean value of the migrant concentration in a near-shore area for the computational term.

\section{2) The bioaccumulating of pollutants by the earth plants.}

The earth plants have property to occlude some chemical agents keeping in soil. However it has appeared valid only for some substances and kinds of plants. For earth plants the coefficient of accumulation varies no more than on one order. There are some routes of accumulation and reallocating of chemical agents from soil into plants. It is:

- the consumption of pollutants by plant roots;

- the accumulation of volatile chemical substances discharged from soil by leaves;

- the accumulation of chemical substances from soil particles and dust by leaves [4].

Thus it is necessary to account all these processes for definition of a total bioaccumulation of pollutants by earth plants.

3) The dilution of sewages.

This process is considerable for rather big reservoirs and rivers only. There are a lot of methods for estimation of the process $[5,6,7]$, therefore we shall not consider this process in the present paper.

\section{4) The evaporation.}

Substance transfer from water solution into atmosphere at natural conditions is called volatility. The speed of a volatilizing is determined under the formula:

$$
F=k \times c
$$

here $\mathrm{F}$ - the flow of matter; $\mathrm{k}$ - the common transport speed; $\mathrm{c}$ - the difference of substance concentration in water and gas phase. 


$$
k=\left[1 / k_{1}+R \times T / k_{2} \times H\right]
$$

here $\mathrm{k}_{1}$ - the transport speed in liquid; $\mathrm{k} 2$ - the transport speed in gas; $\mathrm{R}$ - the universal gas constant; $\mathrm{T}$ - the absolute temperature; $\mathrm{H}$ - the Henry's constant.

If initial concentration of substance in atmosphere equal 0 , the concentration in water solution will decrease on exponential law:

$$
C_{4}=C_{0} \exp \left(-\frac{k}{l} \times t\right)
$$

here 1 - the depth concerning a surface of water; $t$ - the time period [4].

This process is considerable for substances well solvable and easy evaporated from water (for example, acetone).

\section{5) The sedimentation of pollutants.}

Sedimentation of suspended matters is one of major gears determining intensity of a selfcleaning and formation of quality of water. This complex process consists of adsorption by suspended particles, bio-sedimentation, convective transfer and etc. The importance of these processes is different for the different reservoirs and pollutants types. For example, the quantity of pesticides in water can decrease on $15-20 \%$ because of sorption by suspended particles. The mathematical models of these processes are shown in a lot of papers $[8,9]$ and we shall not consider the processes in present paper.

6) The bioaccumulating and degradation of pollutant substances by water plants and microorganisms.

The kinetics of bioconcentrating of chemical agents from water by the aquatic organisms is described by following equations [4]:

$$
\begin{aligned}
& d C_{A} / d t=\gamma_{1} \times C_{w}-\gamma_{2} \times C_{A} \\
& C_{A}^{t}=\frac{\gamma_{1}}{\gamma_{2}} \times C_{w} \times\left(1-e^{-\gamma_{2} t}\right) \\
& C_{A}^{s}=\frac{\gamma_{1}}{\gamma_{2}} \times C_{w}=C B C \propto C_{w}
\end{aligned}
$$

here $C_{A}$ - the concentration of substance in an organism; $t$ - the time period; $\gamma_{1}-$ the constant of consumption speed; $C_{w}-$ the concentration of substance in water; $\gamma_{2}$ - the constant of allocation speed; $\mathrm{C}_{\mathrm{A}}{ }^{\mathrm{s}}$ - the equilibrium concentration of substance in an organism; $\mathrm{CBC}-$ the coefficient of bioconcentrating.

The coefficients of bioconcentrating of different chemical substances in aquatic organisms differ at least on 5 orders depending on physical-chemical properties of the substance and kind of organisms.

7) The biochemical and physical-chemical processes of transformation of pollutants in water.

Using of non-conservation coefficients $\left(k_{n}\right)$ is an approach for quantity estimation of these effects. The coefficients allow for speeds of substances transformation totally.

In general, the kinetics of process of the biochemical transformation may be determined under the formula [5]: 


$$
C_{1}=C^{\bullet} \exp \left(-\left(k_{n, 1}+k_{n, 2}+\cdots+k_{n, m}\right) t\right)
$$

here $C^{*}$ and $C_{t}-$ the substance concentration in initial time and time $t$ accordingly; $k_{n, i}-$ the non-conservation coefficients (apply to account a single process of substances transformation in water).

For practice, we can account only main process of substance transformation and neglect the processes having minor value. In this case:

$$
C_{t}=C^{\bullet} \exp \left(-k_{n} \times t\right)
$$

\section{CONCLUSIONS}

1. It is obviously, that mathematical modeling of physical, chemical and biological processes of waste water treatment in natural systems is necessary for correct calculation of selfcleaning capacity of the natural systems and its preservation.

2. Introduced methods of a rating of different processes of pollutants concentration decreasing and clearing of sewages in natural systems are simplified. For practice these methods may be modified depending on the treatment system, type of contamination, quantity and the quality of initial information.

\section{REFERENCES}

1. Sohrokov, A.H. (1998) Ecological basis of the land and water resources protection in agricultural - industrial complex. Nal'chik, 197 p. (on Russian)

2. Drujinin, N.I., Shishkin, A.I. (1989) Mathematical modeling and forecasting of the Earth surface waters contamination. Leningrad: Hydrometeoizdat, 390 p. (on Russian)

3. Kosov, V.I., Shul'gin, D.F. (1994) The theoretical basis of ecology and rational nature using. Tver', 187 p. (on Russian)

4. Korte, F., Behadir, M., Klein, W. (1997) Ecological chemistry. Moskow: "Mir”, 395 p. (on Russian)

5. Vladimirov, A.M., Layahin, Yu.I., Matveev, L.T. and etc. (1991) Environmental protection. Leningrad: Hydrometeoizdat, 423 p. (on Russian)

6. (1981) Mathematical models of water pollution control. Moskow: "Mir", 471 p. (on Russian)

7. Paal', L.L. (1972) Calculation of waste waters dilution. In: Water quality and fishery of rivers and reservoirs. Moskow, pp. 35 - 50 (on Russian)

8. Hoefler, K. (2001) Kinematic model of sedimentation of polydisperse suspensions. From Internret.

9. Burger, R., Karlsen, K.H., Klingenberg, C. and etc. (2001) A front tracking approach to a model of continuous sedimentation in ideal clarifier-thickener units. From Internret. http://www.math.ntnu.no/conservation/2001/021.pdf 